\title{
Light and scanning electron microscopy of fallow deer (Dama dama) spermatozoa*
}

\author{
B. Gosch, T. Bartolomaeus $\dagger$ and K. Fischer \\ Arbeitsgruppe für vergleichende Hormonphysiologie, I. Zoologisches Institut, and $\dagger$ Abteilung für \\ Morphologie und Systematik, II. Zoologisches Institut, Berliner Strasse 28, D-3400 Göttingen, \\ Federal Republic of Germany
}

\begin{abstract}
Summary. No basic differences in size (mean \pm s.d. for at least 300 spermatozoa), shape and ultrastructure of the spermatozoa of fallow deer were detected (1) in comparison to other artiodactyls, (2) between different fallow bucks, and (3) between different months of the fertile season.

The total length of the normal spermatozoon was $67 \cdot 2 \pm 1 \cdot 2 \mu \mathrm{m}$. The flat, paddleshaped head was $8.2 \pm 0.3 \mu \mathrm{m}$ long, $4.4 \pm 0.2 \mu \mathrm{m}$ for the greatest width, $1.9 \pm 0.2 \mu \mathrm{m}$ for basal width and, $\sim 0.7 \mu \mathrm{m}$ in thickness. The tail measurements were $13.7 \pm 0.3 \mu \mathrm{m}$ for the midpiece, $0.5 \pm 0.1 \mu \mathrm{m}$ for the diameter of the midpiece, $42.6 \pm 0.9 \mu \mathrm{m}$ for the principal piece, and $2.7 \pm 0.6 \mu \mathrm{m}$ for the endpiece. Spermatozoa with abnormalities such as cytoplasmic remnants and droplets, bent and coiled tails, as well as microcephalic forms were observed.
\end{abstract}

Keywords: fallow deer; scanning electron microscopy; light microscopy; spermatozoa; morphology

\section{Introduction}

Light and electron microscopy have been used extensively to examine the structure and function of mammalian spermatozoa. However, spermatozoa of deer species have been little studied. Spermatozoa from moose (Alces alces) were investigated by transmission electron microscopy (TEM) by Andersen (1973), and light microscopical illustrations of normal and abnormal sperm cells have been published for sika deer (Cervus nippon) (Wislocki, 1949), white-tailed deer (Odocoileus virginianus borealis) (Bierschwal et al., 1970), reindeer (Rangifer tarandus) (Dott \& Utsi, 1971), and wapiti (Cervus elaphus nelsoni) (Haigh et al., 1985). Gosch \& Fischer (1989) published micrographs of fallow deer spermatozoa and correlated the occurrence of specific aberrations to seasons.

The purpose of this study is to provide basic data on fallow deer sperm dimensions and to describe the surface fine structure of normal and various abnormal types of spermatozoa.

\section{Materials and Methods}

Animal handling, semen appraisal and sperm staining. Details are given by Gosch \& Fischer (1989).

Light microscopy. With the exception of the width of the midpiece, there were no significant differences in size and shape between unfixed, unstained and Farelly-stained spermatozoa. Measurements were therefore carried out with stained smears. The width of the midpiece was estimated by examining unstained sperm cells. All measurements were performed under phase-contrast illumination (oil-immersion $\times 1250$ ) and by use of a calibrated adjustable ocular micrometer (Leitz GmbH Wetzlar, FRG). To test for interindividual variations and seasonal fluctuations in each sperm dimension, up to 12 specimens collected from Bucks IV, V and $\mathrm{Z}$ between late September and mid-April were investigated. From each specimen, at least 25 normal spermatozoa were measured and so, for each estimation of each sperm dimension, up to 375 sperm cells were viewed.

* Reprint requests to Prof. Dr K. Fischer. 
Table 1. Semen characteristics of specimens prepared for scanning electron microscopy (for precise information about semen appraisal see Gosch \& Fischer, 1989)

\begin{tabular}{lccccccc}
\hline $\begin{array}{l}\text { Sample } \\
\text { date }\end{array}$ & Deer & Fraction & $\begin{array}{c}\text { Volume } \\
(\mathrm{ml})\end{array}$ & $\begin{array}{c}\text { Normal } \\
\text { Density } \\
\text { [spermatozoa/ml] } \times 10^{6}\end{array}$ & $\begin{array}{c}\text { Motile* } \\
\text { spermatozoa } \\
(\%)\end{array}$ & $\begin{array}{c}\text { Grade } \dagger \\
\text { spermatozoa } \\
(\%)\end{array}$ & $\begin{array}{c}\text { of } \\
\text { motility }\end{array}$ \\
\hline $27 \mathrm{Feb}$. & Z & I & 0.7 & 1630 & 71 & 80 & 3 \\
& Z & II & 0.5 & 410 & n.e. & 60 & 3 \\
$27 \mathrm{Feb}$. & V & I & 0.8 & 1030 & 74 & 90 & 4 \\
& V & II & 0.5 & 120 & n.e. & 60 & 3 \\
$21 \mathrm{Mar}$. & Z & - & 1.0 & 340 & 75 & 90 & 4 \\
$21 \mathrm{Mar}$. & V & - & 0.8 & 1460 & 82 & 90 & 4 \\
6 May & IV & - & 1.0 & 60 & 25 & 60 & 3 \\
\hline
\end{tabular}

n.e. $=$ Not estimated.

*Estimated to the nearest $10 \%$.

$\uparrow$ The grade of motility was rated 0 to 4 .

Classification of spermatozoa. Although there are no universally accepted criteria for the assessment of normality or abnormality (Berényi \& Corradi, 1982), artiodactyl spermatozoa with oval, regularly outlined, paddle-shaped heads, straight tails and without any protoplasmic remnants at all are generally considered to be normal. Spermatozoa were rated according to this definition. Sperm cells with amorphous and extremely small heads ( $\leqslant 50 \%$ of normal size) were classified as microcephalic forms.

Scanning electron microscopy. Immediately after collection, $1-2$ drops of the raw semen were diluted in $1 \mathrm{ml} 0.7 \%$ $(\mathrm{w} / \mathrm{v}) \mathrm{NaCl}$. This solution was given dropwise into $5 \mathrm{ml}$ fixative of $2.5 \%(\mathrm{w} / \mathrm{v})$ glutaraldehyde in $0.1 \mathrm{M}$-sodium cacodylate buffer $\left(\mathrm{pH} \mathrm{7.2)}\right.$ for $1 \mathrm{~h}$ at $4^{\circ} \mathrm{C}$. To wash away the fixative and proteins, the suspension was centrifuged $(750 \mathrm{~g}$, $2 \mathrm{~min}$ ) and then resuspended in $0 \cdot 1 \mathrm{M}$-sodium cacodylate buffer $\left(\mathrm{pH} 7 \cdot 2,4^{\circ} \mathrm{C}\right) 5$ times. The pellets were then postfixed in $0.2 \%(\mathrm{w} / \mathrm{v}) \mathrm{OsO}_{4}$, buffered in $0 \cdot 1 \mathrm{M}$-sodium cacodylate $\left(30 \mathrm{~min}, 4^{\circ} \mathrm{C}\right)$ and dehydrated by several centrifugations in an acetone series. The spermatozoa were dried for $3-12 \mathrm{~h}$ at $21^{\circ} \mathrm{C}$, sputter-coated with gold and examined by scanning electron microscopy (Zeiss-Novoscan).

Specimens were collected on 27 February 1986 and 21 March 1986 from Bucks Z and V. A single ejaculate, donated by Buck IV on 6 May 1986, was added. If available, only aliquants of the first semen fraction were prepared. The specimens were assessed as shown in Table 1.

\section{Normal spermatozoa}

Results

The spermatozoa consist of a flat paddle-shaped head and a three-piece tail, which is subdivided into a midpiece, a principal piece, and an endpiece (Figs 1b, e \& h). The head is formed by a head

Fig. 1. SEM and LM micrographs of normal fallow deer spermatozoa. For terminology of morphological features see Hancock (1966) and Matano et al. (1976). (a) Top view of a sperm head. The postnuclear sheath border (PSB), separating the anterior region from the posterior region, and the posterior ring (PR) are clearly visible. Sample, $21 \mathrm{March}$. Bar $=2 \mu \mathrm{m}$. (b) Semilateral view of an entire spermatozoon. Midpiece (MP), principal piece (PP), and endpiece (EP) of the tail are well distinguishable. Sample, 21 March. Bar $=5 \mu \mathrm{m}$. (c) Top view of a sperm head with complete midpiece (MP). Small and regularly arranged mitochondria form a tight coiling around the middle axis. A short junction piece (JP) connects the head with the MP. The annulus (AN) marks the posterior end of the MP. Sample, 27 February. Bar $=5 \mu \mathrm{m}$. (d) The semi-lateral view impressively reveals the flattened shape of the sperm head. Note the apical ridge (AR) and the equatorial segment (ES). Sample, 27 February. Bar $=2 \mu \mathrm{m}$. (e) Differential-interference-contrast micrograph of 2 Farelly-stained spermatozoa. Head cap (HC), postnuclear sheath (PS). Most of the features mentioned above are visible too. Sample, 9 January. Bar $=10 \mu \mathrm{m}$. (f, g) Views of the posterior portion of the sperm head with the insertion of the tail. Note the prominent apical ridge (AR) and the short junction piece (JP). Sample, 27 February. Bar $=2 \mu \mathrm{m}$. (h) Posterior end of the principal piece (PP) with the endpiece (EP). Sample, 27 February. Bar $=2 \mu \mathrm{m}$. 


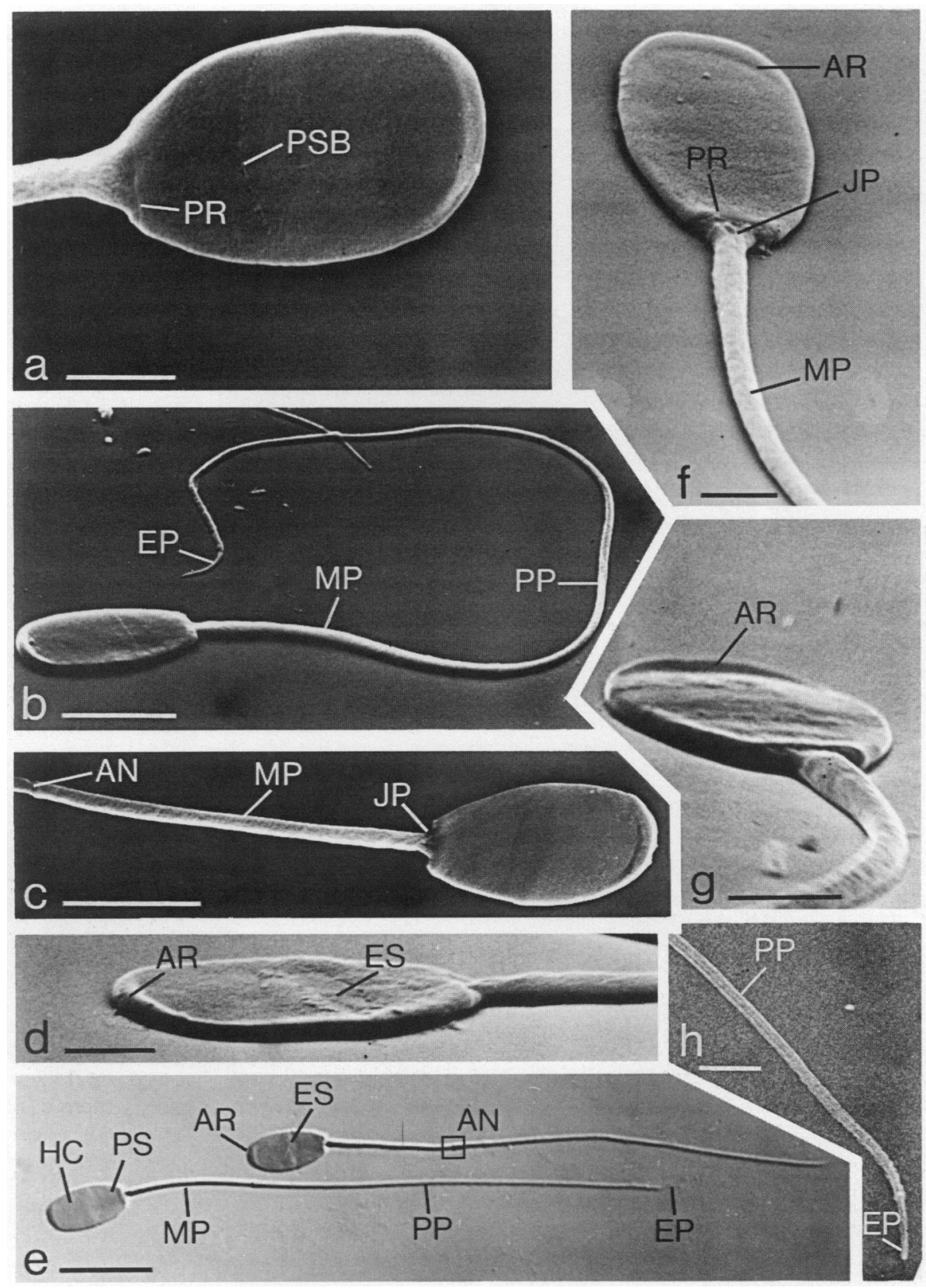


B. Gosch et al.

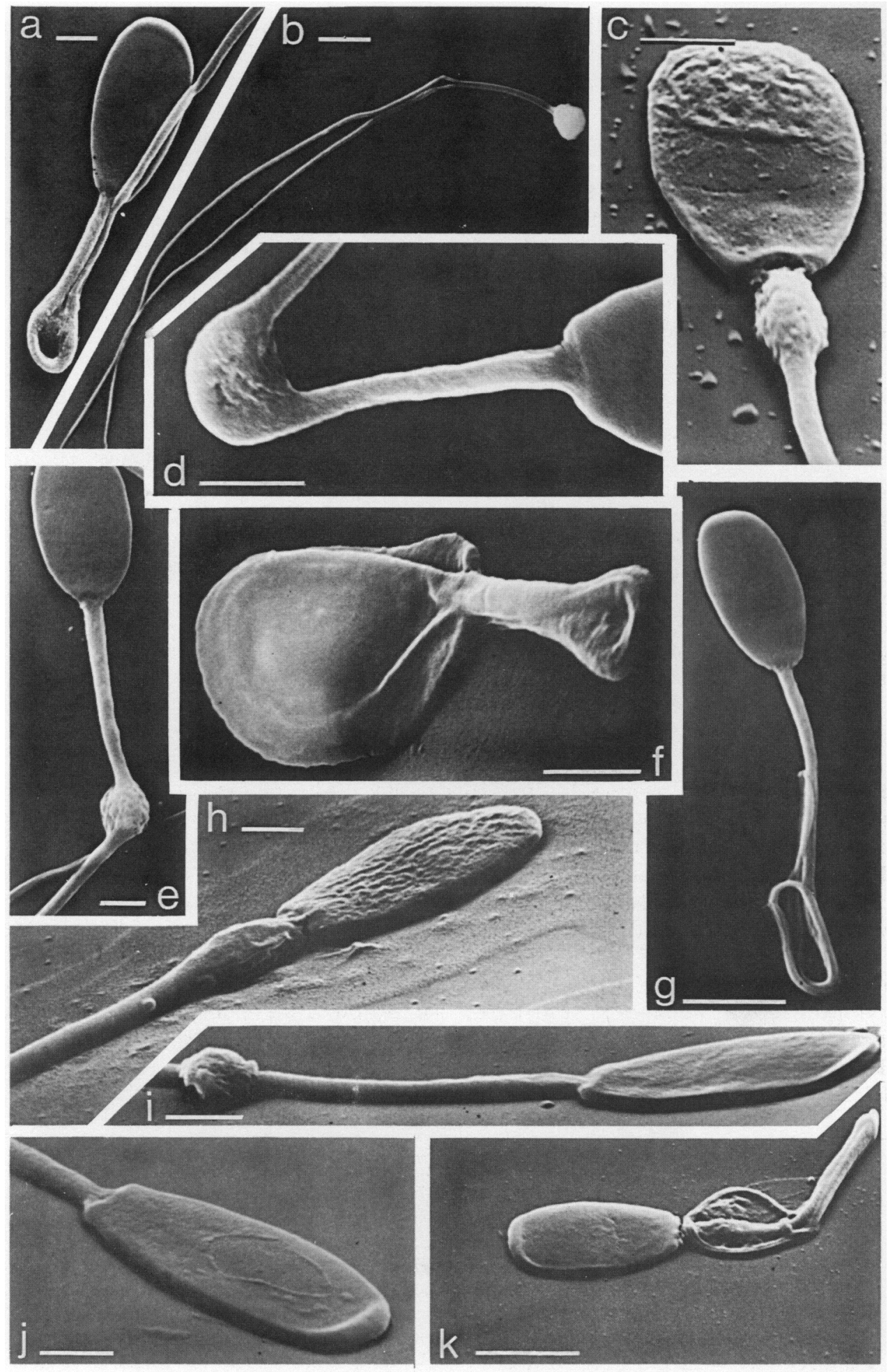


cap, an equatorial segment and the postnuclear sheath (Figs 1d and e). The apical margin of the head cap is elevated and forms the apical ridge (Figs $1 \mathrm{~d}, \mathrm{f} \& \mathrm{~g}$ ). The head is connected to the midpiece by a very short junctional piece, i.e. neck (Figs $1 \mathrm{c} \& \mathrm{f}$ ). The midpiece contains small and regularly arranged mitochondria forming a tight coiling around the middle axis (Fig. Ic). There is a junction between the mid- and the principal piece, the so-called Jensen's ring or annulus (Figs Ic \& e). The principal piece gradually tapers out towards the endpiece, shrinking in diameter by about $50 \%$. The endpiece is characterized by an abrupt narrowing (Fig. $1 \mathrm{~h}$ ).

There were no significant differences in size (mean \pm s.d.) between spermatozoa of different bucks, or between sperm cells collected at different months. The sperm dimensions were: total length, $67.2 \pm 1.2 \mu \mathrm{m}$; head length, $8.2 \pm 0.3 \mu \mathrm{m}$; head width at its widest point, $4.4 \pm 0.2 \mu \mathrm{m}$; head width at its base, $1.9 \pm 0.2 \mu \mathrm{m}$; head thickness, $\sim 0.7 \mu \mathrm{m}$; midpiece, $13.7 \pm 0.3 \mu \mathrm{m}$; diameter of midpiece, $0.8 \pm 0.1 \mu \mathrm{m}$; principal piece, $42.6 \pm 0.9 \mu \mathrm{m}$; endpiece $2.7 \pm 0.6 \mu \mathrm{m}$.

\section{Abnormal spermatozoa}

Various morphological abnormalities of sperm cells were detected by scanning electron microscopy. The most common malformations seem to be cytoplasmic remnants and droplets (Figs $2 \mathrm{c}-\mathrm{e}, \mathrm{h} \& \mathrm{i}$ ), bent and coiled tails (Figs $2 \mathrm{a}, \mathrm{f}, \mathrm{g} \& \mathrm{k}$ ) as well as various surface detachments (Figs 2c, h \& j). Aberrations such as double tails or microcephalic forms (Fig. 2b) were only rarely seen. Cytoplasmic droplets were present proximally (Figs $2 \mathrm{c} \& \mathrm{~h}$ ) as well as translocating (Figs 2d, e $\&$ i). The latter was often associated with bent midpieces (Figs $2 a \& d$ ). Figure 2 shows some intermediate stages from a lightly bent tail (Fig. 2e) to a bent tail forming a loop (Fig. 2a) and finally to totally coiled ones (Figs $2 \mathrm{f} \& \mathrm{k}$ ). With the exception of the microcephalic abnormality (Fig. 2b), aberrations of the head were due to different degrees of surface detachments (Figs $2 \mathrm{c}, \mathrm{h} \& \mathrm{j})$.

\section{Discussion}

The preparation procedure applied is time saving (total $\sim 5 \mathrm{~h}$ ) and easy to carry out. Numerous washing steps and centrifugations produced spermatozoa almost free of debris, and $3 \mathrm{~h}$ of air drying was satisfactory. Although air drying of the preparations will have increased the prominence of denser components, no essential structural artefacts are to be expected (Matano et al., 1976).

From this study it is evident that there are no basic differences in size, shape and ultrastructure between fallow deer spermatozoa and sperm cells of other cervids (Wislocki, 1949; Bierschwal et al., 1970; Dott \& Utsi, 1971; Andersen, 1973; Haigh et al., 1985) or related artiodactyls (Gould et al., 1975; Matano et al., 1976; Cummins \& Woodall, 1985). The general conformation of artiodactyl spermatozoa can therefore be described as a flat paddle-shaped head, with an apical ridge, that can be subdivided into a head cap, an equatorial segment and a postnuclear sheath. A short neck connects the head with the tail, which is subdivided into a midpiece, a principal piece and an endpiece and has a junction between principal and midpiece (Jensen's ring, annulus).

Fig. 2. SEM micrographs of abnormal fallow deer spermatozoa. (a) Midpiece bent at distal cytoplasmic droplet. Sample, 21 March. Bar $=2 \mu \mathrm{m}$. (b) Microcephalic feature with doubletail aberration. Sample, 21 March. Bar $=5 \mu \mathrm{m}$. (c) Spermatozoon with proximal cytoplasmic droplet. Note the damaged surface of the sperm head. Sample, 6 May. Bar $=2 \mu \mathrm{m}$. (d, e) Spermatozoa with bent tails caused by distal cytoplasmic droplets. Sample, 21 March. Bar $=2 \mu \mathrm{m}$. (f, g) Spermatozoa with totally coiled tails. Samples, 6 May and 27 February respectively. $\mathrm{Bar}=2 \mu \mathrm{m}$. (h) Spermatozoon with irregular proximal droplet. Note the damaged surface of the sperm head. Sample, 6 May. Bar $=2 \mu \mathrm{m}$. (i) Spermatozoon with distal droplet. Sample, 27 February. Bar $=2 \mu \mathrm{m}$. (j) Spermatozoon with surface detachment of unknown nature. Sample, 27 February. Bar $=2 \mu \mathrm{m}$. (k) Spermatozoon with coiled tail. Note the cytoplasmic remnant which probably caused the loop. Sample, 6 May. Bar $=5 \mu \mathrm{m}$. 
Fallow deer bucks are probably fertile during the time they are in hard antlers (Gosch \& Fischer, 1989). It is therefore not surprising to obtain intact spermatozoa in specimens sampled up to 5 months after the rut (mid-October/early November).

The ejaculates of mammals always contain abnormal spermatozoa to different degrees. Spermatozoa with distal protoplasmic droplets in particular (Figs $2 \mathrm{~d}$, e $\&$ i) are quite common (Hassan et al., 1980). They are generally referred to as being immature, as the droplets are normally lost during passage through the epididymis. The incidence of coiled tail defects (Figs $2 \mathrm{a}, \mathrm{g} \& \mathrm{k}$ ), is also well described. According to Zemjanis (1969), as many as 10-20\% of sperm cells in normal ejaculates may have bent tails. This abnormality is often due to translocating droplets (Saacke, 1970). The bent and kinked tails illustrated in Figs 2(a), (d) and (e) were always associated with protoplasmic remnants.

Unlike these widespread malformations, the large, irregular proximal droplets seen in association with surface detachments of the head (Figs $2 c \& h$ ) probably reflected an overall decline in testicular function after antler casting (late April/early May). These specific aberrations also often occurred with the recommencement of fertility in the second half of August (Gosch \& Fischer, 1989). Haigh et al. (1985) described similar abnormalities in wapiti spermatozoa at the end of the fertile season.

Microcephalic features and double-tail aberrations (Fig. 2b) were scarce in fallow deer during the season of high fertility but often predominant in ejaculates from late July/first half of August (Gosch \& Fischer, 1989), i.e. the time of transition between sexual quiescence and the recommencement of fertility.

We thank Prof. Dr K. Fischer's team for their assistance in animal handling. The work was supported by the Niedersächsisches Ministerium für Ernährung, Landwirtschaft und Forsten, Hannover, FRG (grant No. 113/477.301), as well as by the Niedersächsische Jägerschaft.

This study is submitted by B.G. in partial fulfilment of the requirements for the degree of Dr. rer. nat.

\section{References}

Andersen, K. (1973) Morphological and ultrastructural studies of moose spermatozoa. Acta vet. scand. 14, 81-91.

Berényi, M. \& Corradi, G. (1982) A simple staining method for the morphologic classification of spermatozoa. Inter. Urol. Nephrol. 14, 185-188.

Bierschwal, C.J., Mather, E.C., Martin, C.E., Murphy, D.A. \& Korschgen, L.J. (1970) Some characteristics of deer semen collected by electroejaculation. J. Am. vet. med. Assoc. 157, 627-632.

Cummins, J.M. \& Woodall, P.F. (1985) On mammalian sperm dimensions. J. Reprod. Fert. 75, 153-175.

Dott, H.M. \& Utsi, M.N.P. (1971) The collection and examination of semen of the reindeer (Rangifer tarandus). J. Zool., Lond. 164, 419-424.

Gosch, B. \& Fischer, K. (1989) Seasonal changes of testis volume and sperm quality in adult fallow deer (Dama dama) and their relationship to the antler cycle. $J$. Reprod. Fert. 85, 7-17.

Gould, K.G., Martin, D.E. \& Hafez, E.S.E. (1975) Mammalian spermatozoa. In Atlas of Mammalian Reproduction, pp. 42-57. Ed. E. S. E. Hafez. Thieme, Stuttgart.

Haigh, J.C., Barth, A.D., Cates, W.F. \& Glover, G.J.
(1985) Electro-ejaculation and semen evaluation of wapiti. Bull. R. Soc. N.Z. 22, 197-203.

Hancock, J.L. (1966) The ultra-structure of mammalian spermatozoa. In Advances in Reproductive Physiology, pp. 125-154. Ed. A. McLaren. Logos Press, London.

Hassan, J., Braun, J. \& Leidel, W. (1980) Nachweis and Vorkommen von Protoplasmatröpfchen im Sperma der Haustiere. Zuchthygiene 15, 15-20.

Matano, Y., Matsubayashi, K., Omichi, A. \& Ohtomo, K. (1976) Scanning electron microscopy of mammalian spermatozoa. Gunma Symp. Endocrinol. 13, 27-48.

Saacke, R.G. (1970) Morphology of the sperm and its relationship to fertility. Proc. $3 r d$ Tech. Conf. Artif. Insem. Reprod. 3, 17-30.

Wislocki, G.B. (1949) Seasonal changes in the testes, epididymides and seminal vesicles of deer investigated by histochemical methods. Endocrinology 44, $167-122$.

Zemjanis, R. (1969) Semen examination. In Veterinary Clinical Pathology, pp. 497-510. Eds W. Medway, J. E. Prier \& J. S. Wilkinson. Williams \& Wilkins Co., Baltimore.

Received 16 December 1988 